\title{
A cysteine proteinase in the penetration glands of the cercariae of Cotylurus cornutus (Trematoda, Strigeidae)
}

\author{
Tadeusz Moczoń
}

Received: 30 June 2010 / Accepted: 30 September 2010 / Published online: 28 October 2010

(C) The Author(s) 2010. This article is published with open access at Springerlink.com

\begin{abstract}
A cysteine proteinase from the penetration glands of Cotylurus cornutus cercariae was examined with histochemical and biochemical methods. The enzyme hydrolyzed gelatin, azocoll, azocasein, azoalbumin, $N$-blocked-L-arginine-4-methoxy-2-naphthylamide, and $N$ blocked-p-nitroanilide, but did not degrade elastin. The metal ion complexane ethylenediamine tetraacetate and the thiol-reducing compound dithioerythritol enhanced the proteinase activity, whereas the thiol-blocking compounds $p$-hydroxymercuribenzoate and $N$-ethylmaleimide (NEM) inhibited it. The enzyme was also sensitive to leupeptin but insensitive to soybean trypsin inhibitor. An electrophoretic separation of extract proteins from the cercariae under acidic, non-denaturing conditions and in the presence of $0.1 \%$ gelatin in a polyacrylamide gel revealed the presence of two distinct and three weak transparent bands in the gel resulting from a gelatinolytic activity at $\mathrm{pH} 6.8$. The distinct bands apparently resulted from the activity of the glandular enzyme and lysosomal cathepsin B, whereas the weak ones presumably indicated these enzymes partially degraded in the course of the preparative procedure. No gelatinolysis occurred following treatment of an extract sample with $0.1 \mathrm{mM}$ NEM.
\end{abstract}

$\begin{array}{ll}\text { Abbreviations } & \\ \text { DTE } & \begin{array}{l}\text { Dithioerythritol } \\ \text { Z-Arg-NhnapMeO }\end{array} \\ & \begin{array}{l}\text {-benzyloxycarbonyl-L-arginine-4- } \\ \text { methoxy-2-naphthylamide }\end{array} \\ \text { Tris } & \begin{array}{l}\text { Amino-2-hydroxymethyl-1,3-pro- } \\ \text { panediol }\end{array}\end{array}$

T. Moczoń $(\square)$

W. Stefański Institute of Parasitology,

Polish Academy of Sciences,

Twarda 51/55,

00-818 Warszawa, Poland

e-mail: moczon@twarda.pan.pl

\section{CHES}

EDTA

Bz-Arg-NHnan

pHMB

NEM

PMSF

STI
2-(N-cyclohexylamino)ethanesulfonic acid

Disodium ethylenediaminetetraacetate

$\mathrm{N}$-benzoyl-L-arginine-4-nitroanilide Sodium $p$-hydroxymercuribenzoate

$N$-ethylmaleimide

Phenylmethanesulfonyl fluoride

Soybean trypsin inhibitor

\section{Introduction}

Mature specimens of Cotylurus cornutus inhabit the intestine of waterfowl. Cercariae of the parasite, after their emergence from water mollusks, invade water invertebrates, mainly leeches and mollusks, by penetrating their teguments. Following migration, the larvae settle in the host's tissues where they grow and transform into metacercariae. Penetration glands of the cercariae are comprised of four discrete glandular cells situated anteriorly to the ventral sucker. Each cell protrudes anteriorly, thus forming its secretory canal. The canals run toward the oral sucker and open at its surface. At present, the chemical nature of the contents of the penetration glands of the cercariae is unknown. It was previously shown that the presence of cysteine proteinases in the penetration glands is a characteristic feature of the cercariae of the two representatives of Diplostomidae family, Diplostomum pseudospathaceum and Tylodelphys excavata (Moczon 1994a, b; Moczon 2007). The trematodes of the genus Cotylurus belong to the family Strigeidae. Both Strigeidae and Diplostomidae are members of the order Strigeida. It was of interest to examine the penetration glands of $C$. cornutus cercariae to ascertain whether or not the 
presence of cysteine proteinases in the glands might be expected in some other species of the Strigeidae family. This is why the present histochemical and biochemical investigations were undertaken.

\section{Materials and methods}

\section{Histochemistry}

Cercariae of $C$. cornutus, which emerged from snails Planorbarius corneus were concentrated by sedimentation in tap water at $1{ }^{\circ} \mathrm{C}$. Small drops of a dense suspension of the larvae were then transferred onto microscope slides. Excess water was removed and the larvae were kept under a stream of air until dry. Following fixation in a mixture of acetone and chloroform (2:1 or 2:0.6 by volume) for 1-2 min at room temperature, the larvae were covered with a drop of a histochemical medium comprising $0.05 \mathrm{M}$ acetate buffer or 3,3'-dimethylglutaric acid- $\mathrm{NaOH}$ buffer at $\mathrm{pH}$ 5.2-5.8, $1 \mathrm{mM} \mathrm{5-nitrosalicylaldehyde} \mathrm{(initially} \mathrm{dissolved} \mathrm{in} \mathrm{N}, \mathrm{N}$ dimethylformamide), $0.5-1.5 \mathrm{mM}$ dithioerythritol (DTE), $0.5 \mathrm{mM}$ disodium ethylenediaminetetraacetate (EDTA), and $0.1 \mathrm{mM}$ Z-Arg-NHnapMeO (Dolbeare and Vanderlaan 1979). Control specimens were pretreated for $10 \mathrm{~min}$ with $0.1 \mathrm{mM} \mathrm{N}$-ethylmaleimide (NEM) in the buffer. Following 30-45 min of an incubation in the dark, in a moist chamber, the material was examined under a fluorescence microscope for the presence of insoluble fluorescing deposits resulting from coupling of the liberated 4-methoxy-2-naphthylamine to 5-nitrosalicylaldehyde.

\section{Preparation of an extract}

Approximately $100 \mathrm{mg}$ (fresh weight) of pelleted larvae was suspended in $10 \mathrm{mM}$ sodium chloride solution and disrupted by application of three 4-sec ultrasonic bursts at $100 \mathrm{~W}$ (Braun sonifier, model Labsonic L) with intervening cooling at $0^{\circ} \mathrm{C}$. Following centrifugation $\left(10 \mathrm{~min}, 16,000 \times \mathrm{g}, 4^{\circ} \mathrm{C}\right)$ the supernatant was used as a source of proteolytic enzymes. Protein concentration was measured with the Coomassie blue protein quantitation method according to Bradford (1976) using crystalline bovine serum albumin as standard.

Assay of proteolytic activity

Proteolytic activity in the extract was examined at $\mathrm{pH}$ 5.2-9.6 (at $0.4 \mathrm{pH}$ intervals), using azoalbumin, azocasein, and azocoll as substrates (Tomarelli et al. 1949; Charney and Tomarelli 1947; Moczoń 1999). An elastinolytic activity toward elastin-orcein (Schotton 1970) was assayed at pH 6.2-9.6. 3,3'-Dimethylglutaric acid-NaOH buffer ( $\mathrm{pH}$ 5.0-7.2), Tris-
$\mathrm{HCl}$ buffer (pH 7.4-8.8), and CHES-NaOH buffer (pH 9.29.6) covered the whole $\mathrm{pH}$ range. Assay mixtures, $300 \mu \mathrm{l}$ of volume, comprised a $0.07-\mathrm{M}$ buffer, $2 \mathrm{mg}$ of a substrate, $1 \mathrm{mM}$ EDTA, $1 \mathrm{mM}$ DTE, and $13 \mu \mathrm{g}$ of extract protein. Incubation time was $60 \mathrm{~min}$ (for azoalbumin, azocasein, and azocoll), and $24 \mathrm{~h}$ (for elastin-orcein), at $24^{\circ} \mathrm{C}$. Control mixtures were supplemented with the extract at the end of the incubation time.

Peptidase activity was measured spectrophotometrically at the $\mathrm{pH}$ range of 5.2-9.6. Incubation media comprised the above mentioned EDTA-DTE buffers, $55 \mu \mathrm{M} N$-benzoyl-Larginine-4-nitroanilide (Bz-Arg-NHnan) as a substrate and $15.5 \mu \mathrm{g}$ of extract protein. For control, DTE was replaced with $0.1 \mathrm{mM} p \mathrm{HMB}$. Following $10 \mathrm{~min}$ of incubation at room temperature, optical density was read against an extract-free blank. A molar extinction coefficient $\varepsilon_{410}=$ 8,800 was used for calculation of numbers of nanomoles of the substrate hydrolyzed.

\section{Electrophoresis}

Native electrophoresis was performed at $4^{\circ} \mathrm{C}$ at an operative pH of 3.5 (Reisfeld et al. 1962) in a polyacrylamide gel (linear gradient, $T=5 \%, C=2 \%$ to $T=18 \%, C=$ $3.5 \%$; notation of Hjertén 1962) containing $0.1 \%$ gelatin. For control, extract samples treated with $0.1 \mathrm{mM}$ NEM for $10 \mathrm{~min}$ were run in parallel to the untreated ones. After separation, fragments of gel slabs were rinsed in distilled water and transferred to a $0.05-\mathrm{M}$ Tris-maleate- $\mathrm{NaOH}$ buffer, pH 6.8 which was supplemented with $1 \mathrm{mM}$ EDTA and $5 \mathrm{mM}$ 2-mercaptoethanol. Following incubation for $90 \mathrm{~min}$ at $24^{\circ} \mathrm{C}$ under continuous but moderate shaking, the gels were routinely fixed, stained with Coomassie brilliant blue, and examined for transparent zones indicating proteolytic activity.

\section{Activation/inhibition}

Studies on activation/inhibition were performed with the use of azocoll at $\mathrm{pH} 7.2$ as described above. Extract samples were preincubated for $10 \mathrm{~min}$ in the presence of potent proteinase activators/inhibitors prior to the addition of the substrate. A series of appropriate controls (extract was added after removal of the unhydrolyzed substrate) was processed in parallel to the assay mixtures.

\section{Results}

Histochemistry

Golden-yellow fluorescing precipitates were observed in those areas of the body of the cercariae which were 
occupied by the penetration glands and by the secretory canals, both being filled with the secretion produced by the glandular cells (Fig. 1). The intensity of the reaction increased with the elevation of the $\mathrm{pH}$, becoming optimal at the $\mathrm{pH} 5.6$, the highest value at which the reaction product remains microcrystalline for a number of minutes and satisfactorily reflects the examined structures; however, from an unknown reason only one in approximately 100 of the examined specimens revealed a satisfactory pattern of the reaction. Due to the fixation and defatting, as well as to a low magnifying power, the activity of cathepsin B in the whole larval body was poorly perceptible.

\section{Enzyme activity}

The examination of proteolytic activity versus increasing $\mathrm{pH}$ values revealed two peaks, both being especially distinct in the case of the use of azocoll as the substrate (Fig. 2). The minor peak indicated the activity of cathepsin B. The major peak apparently illustrated the highest activity of the glandular proteinase at the $\mathrm{pH}$ range between 6.8 and 7.2. The glandular enzyme degraded azocoll, azocasein, and azoalbumin at the $\mathrm{pH}$ range of 5.2-8.8. Maximum rates of hydrolysis expressed as micrograms of the substrate per hour per microgram of extract protein, at an optimum $\mathrm{pH}$, were 10.4 at $\mathrm{pH}$ between 6.8 and 7.2 for azocoll, 0.64 at $\mathrm{pH} 7.2$ for azoalbumin, and 0.23 at $\mathrm{pH} 7.2$ for azocasein. No hydrolysis of elastin-orcein was detected after $24 \mathrm{~h}$ of incubation at the $\mathrm{pH}$ range of 6.2-9.6. Bz-Arg-NHnan was split at a somewhat lower rate $\left(8.6 \mathrm{nmolmin}^{-1} \mathrm{\mu g}^{-1}\right)$ at an optimum pH between 6.4 and 6.8 (Fig. 3). No liberation of $p$-nitroaniline was recorded in incubation mixtures in which DTE was replaced with $p \mathrm{HMB}$. The electrophoretic separation of extract proteins from the cercariae at the operative $\mathrm{pH}$ of 3.5 , at which the proteinases were practically inactive, revealed the presence of two distinct transparent bands in the gel resulting from a relatively high gelatinolytic activity and three bands resulting from a weak activity (Fig. 4). The

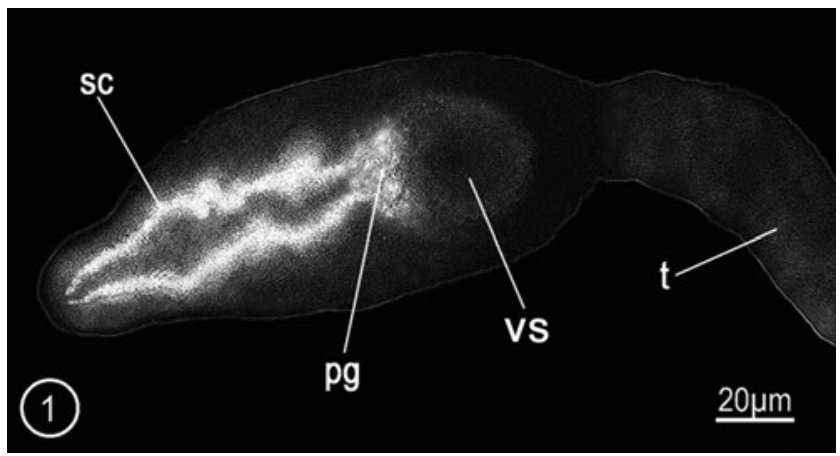

Fig. 1 Hydrolysis of Z-Arg-NHnapMeO by the cysteine proteinase occupying the penetration glands $(p g)$ and the secretory canals $(s c)$ of the cercariae examined with the fluorescence method vs. ventral sucker; $t$, tail

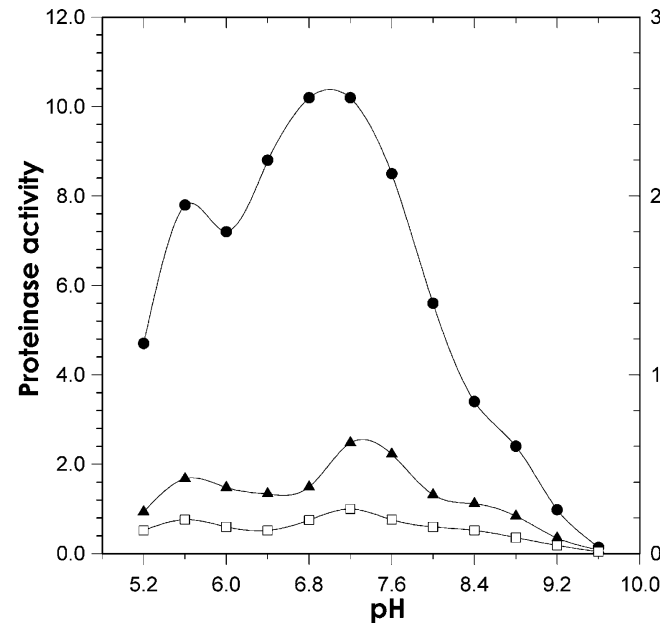

Fig. 2 Rates of hydrolysis of protein substrates observed at differing $\mathrm{pH}$ in the presence of $1 \mathrm{mM}$ EDTA and $1 \mathrm{mM}$ DTE. Proteinase activity is expressed as microgram substrate per hour per extract protein. The left ordinate shows values obtained for azocoll (black circles). The right ordinate shows values obtained for azoalbumin (black triangles) and azocasein (empty squares). Each data point is a mean of duplicate determinations

distinct bands apparently resulted from the activity of the glandular enzyme and cathepsin B, whereas the weak ones presumably indicated these enzymes partially degraded in the course of the preparative procedure. No gelatinolysis appeared in the control gel, thus indicating an irreversible modification of $-\mathrm{SH}$ groups of the enzymes by NEM.

\section{Activation/inhibition}

Calcium ions at $1 \mathrm{mM}$ concentration reduced the proteinase activity by $12 \%$, whereas $0.1 \mathrm{mM}$ zinc sulfate inhibited it (Table 1). 1,10-Phenanthroline, a weak complexane of calcium and magnesium but a strong complexane of zinc, was without an inhibitory effect on the enzyme activity indicating the absence of a zinc-dependent activity of metalloproteinases. EDTA, a strong complexane of divalent and trivalent metal ions produced an increase in the activity

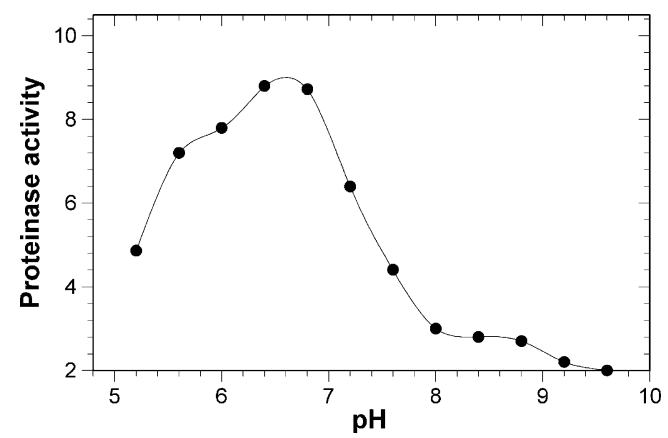

Fig. 3 Rates of hydrolysis of Bz-Arg-NHnan observed at differing $\mathrm{pH}$ in the presence of $1 \mathrm{mM}$ EDTA and $1 \mathrm{mM}$ DTE. Proteinase activity is expressed as nanomoles of the substrate per minute per microgram of extract protein. Each data point is a mean of duplicate determinations 
Fig. 4 Gelatinolysis at $\mathrm{pH} 6.8$ produced by the proteinases separated by electrophoresis at the operative $\mathrm{pH}$ of 3.5 at which the enzymes were practically inactive during migration

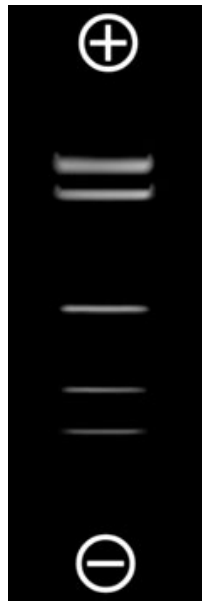

by approximately $20 \%$ by preventing metal ions from an interaction with $-\mathrm{SH}$ groups of cysteine proteinases. DTE, a compound that quantitatively reduces $-\mathrm{SH}$ groups in proteins but does not form stable complexes with $\mathrm{Ca}^{2+}$ and $\mathrm{Mg}^{2+}$, produced an increase in the proteinase activity by about $40 \%$. A combined stimulatory action of EDTA and DTE was stronger than that produced by these individual agents. The inhibition produced by $p H M B$ was in part reversed by DTE, thus proving that the examined enzyme belongs to the family of cysteine proteinases. An almost complete inhibition of the enzyme by leupeptin, a tripeptide

Table 1 Effect of activators/inhibitors on the activity of the cercarial proteinase toward azocoll at an optimum $\mathrm{pH}$ of 6.8

\begin{tabular}{lc}
\hline Compound added & Relative activity (\%) \\
\hline None & 100.0 \\
$\mathrm{CaCl}_{2}, 1 \mathrm{mM}$ & 87.8 \\
$\mathrm{ZnSO}_{4}, 0.1 \mathrm{mM}$ & 1.1 \\
$1,10-P h e n a n t h r o l i n e, 1 \mathrm{mM}^{\mathrm{a}}$ & 103.8 \\
EDTA, $1 \mathrm{mM}$ & 122.4 \\
DTE, $1 \mathrm{mM}$ & 140.2 \\
EDTA $(1 \mathrm{mM})+\mathrm{DTE}(1 \mathrm{mM})$ & $161.4^{\mathrm{b}}$ \\
EDTA $(1 \mathrm{mM})+p \mathrm{HMB}$ & 2.3 \\
$(0.1 \mathrm{mM})$ & \\
As above $+\mathrm{DTE}(1 \mathrm{mM})^{\mathrm{c}}$ & 41.7 \\
Leupeptin, $20 \mu \mathrm{mg} / \mathrm{ml}$ & 3.2 \\
PMSF, $1 \mathrm{mM}$ & 2.2 \\
STI, $0.3 \mathrm{mg} / \mathrm{ml}$ & 102.3 \\
\hline
\end{tabular}

Values represent means of duplicate assays. The incubation media

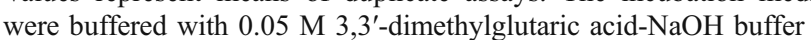

${ }^{a}$ Prepared from a $0.4 \mathrm{M}$ stock solution in dimethylsulfoxide

${ }^{\mathrm{b}}$ Equivalent to the hydrolysis of $10.2 \mu \mathrm{g}$ of azocoll per hour per microgram of extract protein

${ }^{c}$ DTE was added after $10 \mathrm{~min}$ of preincubation in the presence of $p \mathrm{HMB}$

${ }^{\mathrm{d}}$ Prepared from a $0.1-\mathrm{M}$ stock solution in anhydrous isopropanol argininal, provided a further support for this diagnosis. Like cysteine proteinases from other sources, the cercarial enzyme was sensitive to phenylmethanesulfonyl fluoride (PMSF) and was insensitive to soybean trypsin inhibitor (STI).

\section{Discussion}

The described results prove the occurrence of a cysteine proteinase in the penetration glands of the cercariae of $C$. cornutus. Like other enzymes of this family, together with those which were found in the penetration glands of the cercariae of diplostomid trematodes D. pseudospathaceum and T. excavata (Moczoń 1994a, b; Moczon 2007), the glandular proteinase from $C$. cornutus cercariae hydrolyzed gelatin, preferred azocoll over azocasein and azoalbumin, and did not hydrolyze elastin, the latter being a good protein substrate for the elastase-like serine proteinase from the penetration glands of the plagiorchiid Neoglyphe sobolevi cercariae (Moczon 1997). The response of the enzyme extracted from $C$. cornutus cercariae to the treatment with a number of activators and inhibitors (Table 1) was typical for cysteine proteinases and resembled the response of the "penetration enzymes" from the cercariae of the diplostomid trematodes mentioned above.

The chemical factors emitted by the organisms of certain water invertebrates, e.g., leeches and mollusks, which can be responsible for the attraction of the cercariae of the genus Cotylurus, are unknown; however, it is possible that some secreted metabolites or body surface glycoproteins and their fragments (Kalbe et al. 1997) act as effective attractants for the invasive cotylurid cercariae.

The genus Cotylurus belongs to the family of Strigeidae. An acquisition of a sufficient amount of the cercariae of $C$. cornutus for extensive biochemical studies involving a separation and characterization of individual proteinases is rather difficult. Nevertheless, the presented study proved that the penetration glands of the examined larvae synthesize and store a cysteine proteinase which enables the parasite to infect hosts and facilitates the migration through the hosts' tissues. Further work needs to be done to ascertain whether the presence of a similar enzyme in the glandular cells can be extended over other representatives of the Strigeidae family.

Open Access This article is distributed under the terms of the Creative Commons Attribution Noncommercial License which permits any noncommercial use, distribution, and reproduction in any medium, provided the original author(s) and source are credited. 


\section{References}

Bradford MM (1976) A rapid and sensitive method for the quantitation of microgram quantities of protein utilizing the principle of protein-dye binding. Anal Biochem 72:248254

Charney J, Tomarelli RM (1947) A colorimetric method for the determination of the proteolytic activity of duodenal juice. J Biol Chem 171:501-505

Dolbeare F, Vanderlaan M (1979) A fluorescent assay of proteinases in cultured mammalian cells. J Histochem Cytochem 27:14931495

Hjertén S (1962) "Molecular sieve" chromatography on polyacrylamide gels, prepared according to a simplified method. Arch Biochem Biophys suppl 1:147-151

Kalbe M, Haberl B, Haas W (1997) Miracidial host-finding in Fasciola hepatica and Trichobilharzia ocellata is stimulated by species-specific glycoconjugates released from the host snails. Parasitol Res 83:806-812
Moczon T (2007) A cysteine proteinase in the penetration glands of the cercariae of Tylodelphys excavata (Trematoda, Diplostomidae). Parasitol Res 100:299-304

Moczon T (1994a) A cysteine proteinase in the cercariae of Diplostomum pseudospathaceum (Trematoda, Diplostomatidae). Parasitol Res 80:680-683

Moczon T (1994b) Histochemistry of proteinases in the cercariae of Diplostomum pseudospathaceum (Trematoda, Diplostomatidae). Parasitol Res 80:684-686

Moczoń T (1997) An elastase-like endopeptidase in the penetration glands of the cercariae of Neoglyphe sobolevi (Trematoda, Plagiorchiidae). Acta Parasitol 42:115-120

Moczoń T (1999) A metalloproteinase secreted by the infective larvae of Strongyloides papillosus (Nematoda). Acta Parasitol 44:193-198

Reisfeld R, Lewis U, Williams D (1962) Disc electrophoresis of basic proteins and peptides on polyacrylamide gels. Nature 195:281-283

Schotton DM (1970) Elastase. Methods Enzymol 19:113-140

Tomarelli RM, Charney J, Harding ML (1949) The use of azoalbumin as a substrate in the colorimetric determination of peptic and tryptic activity. J Lab Clin Med 34:428-433 